\title{
Causas de perdas em abatedouro de frango de corte relacionadas ao manejo pré-abate*
}

\section{Causes of losses and euthanasia of broilers in emergency poultry slaughterhouse related to pre-slaughter management}

\author{
Camila de Souza Oro, ${ }^{* *}$ Adriano Sakai Okamoto, ${ }^{* *}$ Cauê Bastos Tertuliano dos Santos, ** \\ Ewerton Henrique Alves Silva de Santana, ${ }^{* * *}$ Gabriela Costa Ribeiro, ${ }^{* *}$ Erica Cristina Bueno do Prado Guirro**
}

\begin{abstract}
Resumo
Os mercados importadores de carne de frango brasileira estão se tornando cada vez mais exigentes em relação aos princípios do bem-estar animal na criação e abate de frangos de corte. Desta forma, adaptar a cadeia avícola a tais exigências depende do controle de falhas no manejo pré-abate, que são os principais problemas relacionados ao bem-estar animal na cadeia de produção do frango de corte. Portanto, o objetivo deste estudo foi estabelecer e quantificar as principais causas de perdas relacionadas a falhas no manejo pré-abate em um abatedouro de frangos comerciais. Para tanto, foram implantados ábacos nas três linhas de abate ao lado do local da pendura das aves e registrado o número daquelas que foram eliminadas ou estavam mortas, durante 10 dias, em dois turnos de abate. Durante o estudo foram abatidos 4.563.293 frangos e o total de aves mortas no pré-abate foi de 14.039 aves $(0,3 \%)$. A mortalidade no transporte e/ou galpão de espera foi a principal causa de descarte $(80,56 \%)$, seguida por refugos $(19,1 \%)$, injuriadas $(0,18 \%)$ e fraturadas $(0,11 \%)$. Conclui-se que para reduzir as perdas no pré-abate, os esforços devem ser direcionados principalmente na logística de transporte e em melhorias no galpão de espera, visando a diminuição de perdas por mortalidade nessa etapa.
\end{abstract}

Palavras-chave: Abatedouro, bem-estar animal, pré-abate.

\begin{abstract}
Brazilian chicken import markets are becoming increasingly demanding in terms of adhering to the principles of animal welfare in raising and slaughtering chicken. Thus, adapting the poultry to such requirements requires preslaughter failures control, that are main animal welfare problems in broiler production is preslaughter management. Therefore, the objective of this study was to establish and quantify the main causes of losses related to pre-slaughter management in a commercial chicken slaughterhouse. In this way, abacuses were implanted next to the hanging in the three slaughter lines and the number of broilers eliminated or that were death on arrivals was recorded, for 10 days, in both slaughter shifts. 4.563 .293 broilers were slaughtered in the experiment and the total number of boilers eliminated in the emergency slaughter were 14.039 birds $(0.3 \%)$. The death on arrivals was the leading cause of elimination in emergency slaughter $(80.56 \%)$, followed by small broilers $(19.1 \%)$, injured broilers $(0.18 \%)$ and fractured broilers $(0.11 \%)$. It is concluded that to reduce preslaughter losses, efforts should be directed mainly to transport logistics and improvements in the waiting shed, aiming to decrease mortality losses in this stage.
\end{abstract}

Keywords: Animal Welfare, pre-slaughter, slaughterhouse.

\section{Introdução}

Os mercados importadores da carne de frango brasileira estão cada vez mais exigentes quanto às diretrizes do bem-estar animal. Desta forma, adaptar a cadeia avícola a tais exigências tornou-se estratégia da indústria brasileira na melhoria da qualidade e da imagem de seus produtos e na ampliação de mercados importadores (ABPA, 2016).

Com o objetivo de fomentar os princípios do bem-estar animal no abate de aves no Brasil, o Ministério da Agricultura, Pecuária e Abastecimento (MAPA) firmou, em 2008, um acordo junto a
Sociedade Mundial de Proteção Animal - WSPA e em 2016 a Associação Brasileira de Proteína Animal (ABPA) desenvolveu um protocolo de bem-estar na avicultura como norteador para as empresas avícolas. Além disso, o Ministério da agricultura, pecuária e abastecimento (MAPA) dita medidas para evitar maus tratos aos animais e aplicar ações que visem à proteção e ao bem-estar animal, desde o embarque na origem até o momento do abate, no Regulamento da Inspeção Industrial e Sanitária de Produtos de Origem Animal (RIISPOA).

Segundo o Certified Humane Brasil o bem-estar animal se tornou um assunto de interesse a partir da publicação, em 1964 na

\footnotetext{
${ }^{*}$ Recebido em 30 de setembro de 2019 e aceito em 16 de novembro de 2020

**Docente da UFPR/Setor Palotina; Departamento de Ciências Veterinárias; Palotina, PR, Brasil.

***Acadêmico da UNESP/FCA; Departamento de Produção Animal; Botucatu, SP, Brasil;

Autor para correspondência: camila.oro@unesp.br
} 
Inglaterra, do livro "Animal Machines" escrito por Ruth Harrison, em que a autora alertava como a revolução industrial intensificou a produção dos animais sem considerar o seu bem-estar. As considerações feitas pela autora levaram ao desenvolvimento do Farm Animal Welfare Council que, em 1979, publicou princípios norteadores das boas práticas de bem-estar animal e as legislações sobre o tema, baseados nas cinco liberdades para o bem-estar animal, em que os animais: estejam livres de fome e sede; estejam livres de desconforto; estejam livres de doenças e injúrias; tenham liberdade para expressar os comportamentos naturais da espécie; estejam livres de medo e de estresse.

$\mathrm{Na}$ produção avícola o manejo considerado mais preocupante em relação ao bem-estar animal é o manejo pré-abate. Os pontos críticos que se destacam são: o jejum hídrico e alimentar, que tem como objetivo reduzir a contaminação da carcaça durante a evisceração (PORTARIA N 62, DE 10 DE MAIO DE 2018 Art. 32, RIISPOA); a apanha e acondicionamento dos frangos na caixa; e o transporte (LUDTKE et al., 2010).

Além das perdas com a mortalidade e a eliminação, o estresse do manejo pré-abate pode ser associado a outras consequências como defeitos na qualidade da carne, perda de certificações e de mercado (BARBOSA FILHO et al., 2014).

Diante do exposto, o objetivo do estudo foi estabelecer e quantificar as principais causas de perdas relacionadas ao manejo pré-abate em um abatedouro de frangos comerciais.

\section{Material e métodos}

A colheita dos dados foi realizada durante 10 dias do mês de agosto (21 a 31 de agosto), em dois turnos de abate, em um abatedouro comercial habilitado pelo Serviço de Inspeção Federal (SIF), localizado no estado do Paraná, com média de abate de 500 mil aves/dia.

Para a mensuração das perdas, foram implantados ábacos nas três linhas de abate ao lado do local da pendura das aves. No ábaco existiam as opções de identificação em: death on arrivals (DOA), ou seja, morte no transporte/galpão de espera, refugo, injuriado ("encorujado/apático") e lesionado (frango com alguma contusão ou fratura).

Os dados foram registrados no final de cada carga de frangos pendurados na linha de abate. Foram registradas também as temperaturas mínimas e máximas do ambiente, por meio de sensor fixo, no galpão de espera (Quadro 1), a estrutura e os equipamentos presentes no galpão de espera, o tempo de espera antes do abate; e o peso médio das aves e as dimensões das caixas de transporte, para obtenção da densidade de aves (Kg/ $\mathrm{m}^{2}$ ) por caixa, obtida pela equação a seguir:

$$
\text { Densidade }=\frac{\mathrm{n}^{\circ} \text { de aves na caixa } \mathrm{x} \text { peso médio }}{\text { Área da caixa }\left(\mathrm{m}^{2}\right)}
$$

Quadro 1: Temperaturas mínimas e máximas do ambiente de um abatedouro de frangos no Paraná observadas no sensor de temperatura fixado em galpão de espera entre os dias 21 e 31 de agosto de 2019

\begin{tabular}{|lcc|}
\hline Data & Temperatura mínima & Temperatura máxima \\
\hline $21 / 08 / 2019$ & $6^{\circ} \mathrm{C}$ & $21^{\circ} \mathrm{C}$ \\
$22 / 08 / 2019$ & $9^{\circ} \mathrm{C}$ & $24^{\circ} \mathrm{C}$ \\
$23 / 08 / 2019$ & $13^{\circ} \mathrm{C}$ & $27^{\circ} \mathrm{C}$ \\
$24 / 08 / 2019$ & $18^{\circ} \mathrm{C}$ & $31^{\circ} \mathrm{C}$ \\
$25 / 08 / 2019$ & $18^{\circ} \mathrm{C}$ & $31^{\circ} \mathrm{C}$ \\
$26 / 08 / 2019$ & $17^{\circ} \mathrm{C}$ & $33^{\circ} \mathrm{C}$ \\
$28 / 08 / 2019$ & $18^{\circ} \mathrm{C}$ & $34^{\circ} \mathrm{C}$ \\
$29 / 08 / 2019$ & $18^{\circ} \mathrm{C}$ & $33^{\circ} \mathrm{C}$ \\
$30 / 08 / 2019$ & $16^{\circ} \mathrm{C}$ & $34^{\circ} \mathrm{C}$ \\
$31 / 08 / 2019$ & $17^{\circ} \mathrm{C}$ & $33^{\circ} \mathrm{C}$ \\
\hline
\end{tabular}

\section{Resultados e discussão}

Durante o presente estudo foram abatidos 4.563.293 frangos e destes, $14.039(0,3 \%)$ foram descartados, sendo que 11.315 $(80,56 \%)$ morreram no transporte e/ou galpão, consideradas assim como death on arrivals (DOA), 2.684 (19,1\%) foram considerados como refugos, $25(0,18 \%)$ apresentavam-se injuriados e $15(0,11 \%)$ estavam fraturados (Figura 1).

A principal maneira de avaliar as falhas no manejo pré-abate é pela mensuração das perdas no abate emergencial, porque é nessa etapa que os frangos mortos na chegada à linha de abate devem ser separados para o descarte adequado juntamente com os debilitados e fraturados. Estes últimos, são sacrificados por meio do deslocamento cervical, como preconizado por lei quando apresentam até 3 kg (OMS, 2014; LUDTKE et al., 2010).

Figura 1: Frequência das principais causas de perdas no pré-abate de frangos de corte

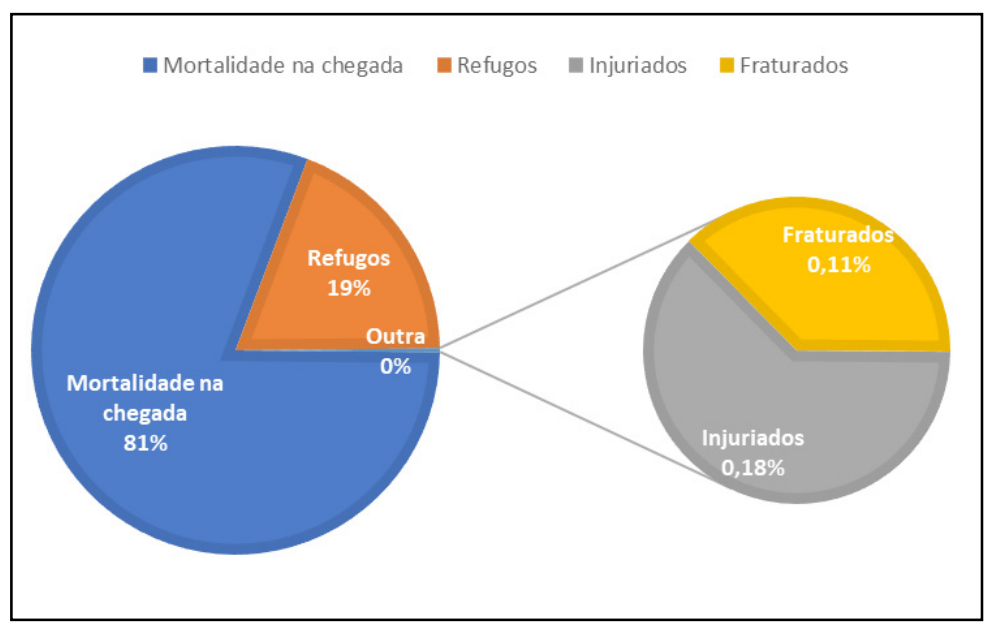


O manejo pré-abate realizado de forma inadequada em relação ao bem-estar animal, pode resultar em mortalidade e eliminação de aves (BARBOSA FILHO et al., 2014). A maior causa de descarte de aves no presente estudo foi de mortos no transporte/e ou galpão de espera (DOA). Nidjam et al. (2004), avaliaram 1.907 lotes de frangos de corte, e observaram porcentagem média de aves DOA de 0,46\%, com valores mínimo e máximo de $0,00 \%$ e $16,61 \%$, respectivamente, próximo do que foi encontrado neste estudo $(0,25 \%)$ quando comparado o número de DOA em relação ao total de aves abatidas. 0 percentual de perdas por mortalidade no transporte e/ou galpão de espera podem persistir ou até mesmo aumentar durante o ano, tornando os prejuízos ainda maiores Silva \& Vieira (2010).

No transporte os frangos estão expostos a diversos fatores estressantes como: jejum alimentar e hídrico, mistura social, perturbações e ruídos, além do estresse térmico (LANA et al., 2018; SIMÕES et al., 2009). Os frangos de corte na fase de abate são mais sensíveis ao calor, devido ao melhoramento genético que aumentou a média de peso ao abate (LOPES et al., 2015), podendo a mortalidade no transporte ser maior em estações do ano com temperaturas mais quentes e dias mais longos. No Brasil, o clima tropical ocorre em boa parte do território, sendo mais difícil proporcionar temperatura de conforto para os frangos no transporte e no galpão de espera (ARISTIDES et al., 2007; SILVA et al., 2011).

No presente estudo, as temperaturas nos dias da coleta se encontravam entre $6{ }^{\circ} \mathrm{C}$, registrada no primeiro dia de coleta e $34{ }^{\circ} \mathrm{C}$ no sétimo e nono dia de coleta. Esses extremos de temperatura apresentam-se fora da faixa de conforto térmico do frango de corte $\left(18^{\circ} \mathrm{C}\right.$ a $\left.28^{\circ} \mathrm{C}\right)$ (LUDTKE et al., 2010), sendo que, com exceção dos dois primeiros dias, as temperaturas altas predominaram, o que pode explicar a alta incidência de frangos mortos no pré-abate.

No presente estudo o peso médio das aves foi de aproximadamente três quilos. Nos caminhões de transporte a densidade foi de até 3.744 aves por carga e oito aves por caixa. A caixa possuía as medidas de 31,5 x 57 x 76,5 cm (altura, largura e comprimento). A área útil por quilo de peso vivo foi de $181,68 \mathrm{~cm}^{2} / \mathrm{kg}$. Segundo Vieira (2012) densidades acima de sete aves por caixa, causam um aumento na mortalidade nas horas mais quentes do dia (tarde), quando comparado às mortes registradas nas horas mais frescas (manhã e noite). Silveira (2013) sugere que, para o conforto do frango de corte, deve haver espaço suficiente para que as aves possam deitar-se sem se acomodarem umas sobre as outras e que possibilite troca de calor com o ambiente.

O tempo de cada carga de frangos no galpão de espera variou entre 30 a 180 minutos. No galpão havia um sistema de nebulização, chuveiros, ventiladores nas laterais e cortinas nas dianteiras e traseiras do galpão. O acionamento dos ventiladores, chuveiros e nebulizadores aconteciam automaticamente conforme a temperatura e umidade do galpão, seguindo o padrão estabelecido no manual da WSPA, escrito por Ludtke et al. (2010). Contudo, a cobertura do galpão no presente estudo, não era suficiente para cobrir os caminhões mais compridos, além de não ser construído com o seu eixo longitudinal orientado no sentido leste-oeste, o que pode ter contribuído para o alto número de mortos no pré-abate.

A segunda maior causa de frangos descartados no pré-abate neste estudo foi a de frangos refugos. Peretti (2017) avaliou 773 aves eliminadas no abate emergencial e encontrou número um pouco maior de frangos refugos (194 ou 25,10\%) e, também foi a segunda maior causa de frangos descartados no abate emergencial.

Aves que refugam possuem menor diâmetro da canela, o que pode resultar na não efetiva insensibilização devido ao pouco contado da ave com a nórea na eletronarcose (LUDTKE et al., 2010). Portanto, não é adequado, em termos de bem-estar animal, que essas aves sejam carregadas para o abate, pois além de não ser permitido a utilização comercial dessas aves, elas passam por estresse desnecessário na apanha e transporte.

Para reduzir o carregamento de refugos é importante realizar treinamentos frequentes com os funcionários terceirizados. Os veterinários que prestam assistência técnica ao produtor também podem contribuir, recomendando aos avicultores que realizem a eutanásia frequente dessas aves (LUDTKE et al., 2010).

As aves injuriadas foram consideradas aquelas que se apresentavam encorujadas (com penas eriçadas), sinal relacionado a mal-estar e apatia nas aves. Os frangos podem ficar debilitados principalmente devido ao jejum pré-abate, que possibilita 0 desenvolvimento de patógenos intestinais; mas pode resultar também do estresse da apanha, principalmente quando realizada de forma inadequada (pescoço ou pés); e estresse térmico do transporte e/ou galpão de espera.

No presente estudo a frequência de aves injuriadas foi menor no que os números registrados em estudos de anos anteriores. Kettlewell e Turner, em 1985, e Nidjam e colaboradores, em 2004, relataram frequências de $5 \%$ e 2,2\%. A diminuição do carregamento de aves injuriadas é concomitante ao aumento da exportação de carne que intensificou a fiscalização nos abatedouros. Segundo o RIISPOA 2017, art. 43, aves doentes ou apáticas não devem ser carregadas para o abatedouro e, quando observadas no pré-abate, devem ser eliminadas emergencialmente pois representam um risco para inocuidade do produto e para a biossegurança do frigorífico (MINISTÉRIO DA AGRICULTURA, PECUÁRIA E ABASTECIMENTO, 2017).

As lesões visíveis, responsáveis por levarem as aves ao abate emergencial, são representadas pelas fraturas, que apresentaram neste estudo frequência inferior ao encontrado por Kettlewell \& Turner (1985), que relataram média percentual de fraturas nas indústrias entre 20 a $25 \%$. A diminuição dessas lesões, que ocorrem principalmente devido a falhas durante a apanha e carregamento dos frangos, se deve ao treinamento constante das equipes de apanha sobre a forma correta de captura (SANTOS et al., 2015). Leandro et al. (2001) avaliaram a apanha de 180.000 aves e os resultados mostraram que aves capturadas pelo dorso apresentaram menor número de contusões de carcaça, do que aquelas que foram pegas pelo pescoço $(1,09 \%$ contra $1,27 \%$, respectivamente).

A fiscalização também foi intensificada com intuito de reduzir os prejuízos causados por contusões e fraturas que resultam na condenação de partes mais nobres da carcaça (coxa, sobrecoxa, asas e peito) (LUDTKE et al., 2010). A conservação das caixas (sem buracos, ausência da tampa ou pontas) também reduziram as contusões e fraturas nos frangos (LUDTKE et al., 2010), além dos avanços tecnológicos de equipamentos para o empilhamento e descarga das caixas de transporte que proporcionaram maior eficiência ao processo e, consequentemente menos contusões nas aves (MARQUES, 2018; SANTOS et al., 2015). 


\section{Conclusão}

Conclui-se que a maior frequência de perdas no pré-abate foi relacionada à mortalidade no transporte e/ou no galpão de

\section{Referências}

ABPA (Associação Brasileira de Proteína Animal). Protocolo de Bem-estar para frangos. 2016. Disponível em: http://www.abpa-br. org. Acessado em 29 out. 2020.

ARISTIDES, L. G. A.; DOGNANI, R.; LOPES, C. F.; SILVA, L. G. S.; SHIMOKOMAKI, M. Diagnósticos de condenações que afetam a produtividade da carne de frangos brasileira. Revista Nacional da Carne, São Paulo, v. 22, n. 368, p. 22-28, 2007.

BARBOSA FILHO, J. A. D.; QUEIROZ, M. L. V.; BRASIL, D. F.; VIEIRA, F. M. C.; SILVA, I. J. O. Transport of broilers: load microclimate during. Brazilian summer. Revista Engenharia Agrícola, vol.34, n.3, p. 405-412, 2014.

CERTIFIED HUMANE BRASIL. Conheça as cinco liberdades do bem-estar animal. 2017. Disponível em: https:// certifiedhumanebrasil.org/conheca-as-cinco-liberdades-dosanimais/. Acessado em 15 out. 2020.

KETTLEWELL, P. J.; TURNER, M. A. A review of broiler chicken catching and transport systems. Journal of Agricultural Engineering Reseach, v. 3, p. 93-114, 1985.

LANA, R. F.; DA CUNHA, A. F. LANA, R. F.; L. F. SANTOS, L. F.; ARAÚJO, F. R.; DA SILVA, M. D. Influência do jejum alimentar na mortalidade, perda de peso vivo, fraturas, hematomas e contaminação de carcaças em abatedouro de frangos. Archives of Veterinary Science, v.23, n.1, p.24-32, 2018.

LEANDRO, N. S. M.; ROCHA, P. T.; STRINGHINI, J. H.; SCHAITL, M.; FORTES, R. M. Efeito do tipo de captura dos frangos de corte sobre a qualidade da carcaça. Ciência Animal Brasileira, v. 2, n. 2, p. 97-100, 2001.

LOPES, J. C. O.; RIBEIRO, M. N.; DE SOUSA LIMA, V. B. Estresse por calor em frangos de corte. Nutritime, v. 12, n. 6, 2015. LUDTKE, C. B.; CIOCCA J. R. P.; DANDIN T.; BARBALHO P. C.; VILELA J. A. Abate humanitário. WSPA - SOCIEDADE MUNDIAL DE PROTEÇÃO ANIMAL. RIO DE JANEIRO / RJ, 2012.

MARQUES, H. L. Industrialização nos ovos e apanha automática de frangos. AVICULTURA INDUSTRIAL, ed. 1274, 2018, 28-31 p.

MINISTÉRIO DA AGRICULTURA, PECUÁRIA E ABASTECIMENTO. Regulamento de Inspeção Industrial e Sanitária de Produtos de Origem Animal (RIISPOA). Disponível em: https://www.gov.br/ agricultura/pt-br/assuntos/inspecao/produtos-animal/arquivos/ decreto-n-9013-2017_alt-decreto-9069-2017_pt.pdf/view. Acessado em 02 de nov. 2020. espera e que os esforços para a redução das perdas devem ser direcionados à logística do transporte e em melhorias no galpão de espera, visando a diminuição de perdas por mortalidade nessa etapa.

NIDJAM, E.; ARENS, P.; LAMBOOIJ, E.; DECUYPERE, E.; STEGEMAN, J. A. Factors influencing bruises and mortality of broilers during catching, transport, and lairage. Poultry Science, v. 83, p. 1610-1615, 2004.

OMS - ORGANIZAÇÃO MUNDIAL DA SAÚDE. Código sanitário de animais terrestres - Capítulo 7.5 Abate dos animais. 2014. Disponível em:<https://www.gov.br/agricultura/ ptbr/assuntos/sustentabilidade/bemestaranimal/arquivos/ Captulo7_5abatedeanimais.pdf> Acessado em 15 out. 2020.

PERETTI, C. Trabalho De Conclusão De Curso Em Agroindústria Da Região Oeste Catarinense Na Área De Abate E Processamento De Aves. Trabalho de Conclusão do Curso de Graduação em Medicina Veterinária da Universidade Federal de Santa Catarina, Campus de Curitibanos, 2017.

RUTH HARRISON. Animal Machine. Stuart (Vincent) \& J.M.Watkins Ltd: Inglaterra, 1964.

SANTOS, J. P. A.; DO VALE, M. M.; KARKOW, A. K.; BRANCO, T.; BEVILAQUA, B.; DOS SANTOS, M. P.; FALCONE, D. B.; Perdas produtivas no pré-abate e carregamento de frangos de corte. Nutritime, v. 12, n. 6, 2015.

SILVA, J. A. O; SIMÕES, G. S.; ROSSA, A.; OBA, A.; MATSUO, T.; SHIMOKOMAKI, M.; IDA, E. I. Manejo pré-abate de transporte e banho sobre a incidência de mortalidade de frangos de corte. Semina: Ciências Agrárias, v. 32, n. 2, p. 795-800, 2011.

SILVA, I. J. O.; VIEIRA, F. M. C. Ambiência Animal E As Perdas Produtivas No Manejo Pré-Abate: O Caso Da Avicultura De Corte Brasileira. Archivos de Zootecnia, n.59, p. 113-131, 2010.

SIMÕES, G. S.; OBA, A.; MATSUO, T. ROSSAR.; SHIMOKOMAKI, M.; IDA, E. I. VEHICLE thermal microclimate evaluation during Brazilian summer broiler transport and the occurrence of PSE (Pale, Soft Exudative) meat. Brazilian Archives Biology and Technology, v.52, p.195- 204, 2009.

VIEIRA, S. L. Qualidade de carcaça de frangos de corte. 2 ed. 2012. 